\title{
Glossary of terms and names
}

\begin{abstract}
Abbott, Andrew. A leading professor of sociology, long based at the University of Chicago, who has theorized sociology in a distinctive way that he calls processual sociology (Abbott 2001, 2016).
\end{abstract}

Argumentation. This is one of four professional activities within a purposive theory of public management, along with sense-making, designing, and dramatization. Argumentation has long been theorized within philosophy, which brings out the character of practical (as opposed to scientific) argumentation. Going back to Aristotle, practical argumentation has been understood to move forward through inexact reasoning on the basis of presumptions that are more like opinions than facts or laws. Such ideas about practical argumentation have been formalized over the last few generations, starting with Toulmin (1958). Argumentation theorists, such as Douglas Walton, have emphasized that practical reasoning is a social phenomenon in being goal-oriented and cooperative. Ideas about argumentation have been combined with ideas about social relations and studied more empirically by sociologists. Chapter 4 identifies argumentation with a sociological theorist, Charles Tilly.

Bardach, Eugene. A major figure in the fields of public policy and public management, now an emeritus professor at the Graduate School of Public Policy of the University of California, Berkeley, where he was based for his entire academic career. Bardach's writings about public management, and especially about research, represent the starting point for developing this book's ideas about public management as a design-oriented professional discipline. These writings, especially, Bardach (1994) and Bardach (2004), are discussed at some length in this book, especially in Chapter 6.

Bryson, John. A leading figure in the professional discipline of public management, and McKnight Presidential Professor of Planning and Public Affairs at the University of Minnesota's Hubert H. Humphrey School of Public Affairs. He is best known by practitioners for his multi-edition book on strategic planning in public and non-profit organizations, which exemplifies mechanism-intent thinking about public organizations and professional practice. This book is featured in the Public Management Gallery Tour, presented in Chapter 4, in the section on purposive theories of public organizations. 
$\boldsymbol{C}+\boldsymbol{M}=\boldsymbol{O}$. A symbolic representation drawn from Pawson and Tilley's (1997) book, Realistic Evaluation. C stands for context, $\mathrm{M}$ for mechanism, and $\mathrm{O}$ for outcome. The arithmetic symbols indicate that outcomes are due to both context and mechanisms. In terms of the present book, $\mathrm{C}+\mathrm{M}=\mathrm{O}$ is a way to represent public programs as purposeful phenomena, focusing on their embodiment designs, with the expression being about the totality of scenario-processes in which a program consists. These ideas are discussed in Chapters 7 and 8.

Conceptual designs. This term is drawn from purposive theorizing about engineering design (Cross 2008). Dating back to late nineteenth-century Germany, this purposive theory holds that designing consists in a sequential stage process. As theorized, the outcome of any given stage within a design process is a "design," that is, a representation of the machine or, more broadly, the purposeful phenomenon, with which the design process is concerned. The sequential stage process theory of engineering design holds that the first stage should eventuate in a conceptual design. A proper conceptual design is meant to be clear about some, but not all, aspects of the purposeful phenomenon with which it is concerned. In simple terms, a proper conceptual design is clear about what the purposeful phenomenon is for, while not resolving the issue of what the purposeful phenomenon should consist in. The essential reason for this view is that it's best for the designer and the client to be in agreement on what a purposeful phenomenon is for, before they move toward settling on the specifics of a technical system, thereby implementing the conceptual design so as to effectuate the phenomenon's purpose. Accordingly, a proper conceptual design - insofar as it represents a purposeful phenomenon's technical system - does so in a high-level way, with emphasis placed on what functionality is needed for the purpose to be effectuated; accordingly, a technical system's outcome pattern, as it operates, would be relevant to a proper conceptual design, whereas a technical system's physical features and its spatial organization would be out-of-place. This idea is pertinent to a design-oriented professional discipline of public management, because it takes public organizations to be purposeful phenomena, to which this discipline is tied. The conceptual bridge from engineering design to public management consists in two steps. The first is the idea that enterprises are purposeful phenomena, which Fayol (1919/1984) developed. The second is that public organizations are enterprises, which Moore (1995) developed. A proper conceptual design of an enterprise (and thus of a public organization) is clear about enterprise-intent. A proper conceptual design of an enterprise is also clear about the totality of enterprise-functions that need to be performed to effectuate enterprise-intent. Further, an enterprise's conceptual design - following Fayol, and illustrated by Porter (1985) and Bryson (2018) - presents a functional breakdown, along with statements about how the performance of one function depends on the performance of one or more other functions. On the other hand, a proper conceptual design of an enterprise is not definitive about the mechanisms for effectuating enterprise intent. Nevertheless, a proper conceptual design of an enterprise can contemplate its enterprise-mechanisms, by presenting them in a "high-level" way. For example, a conceptual design may outline the 
scenario-processes in which enterprise-mechanisms consist, pointing to what social mechanisms (as theorized in processual sociology) would be helpful to activate, or pointing to a scenario-process' desired outcome pattern.

Context. This term is part of the idea of a scenario-process. A scenario-process is a way of representing the embodiment design of purposeful phenomena in public organizations. A scenario process plays the role of mechanism in relation to fulfilling a public organization's intent. The context-activity relation is understood through modeling, drawing on theoretical ideas from processual sociology. The term "context" in this discussion is specifically a reference to dynamically stable properties of scenario-processes. Their causal role is to channel the activity within a scenario-process, which, in turn, is viewed as the direct source of scenario-process outcomes.

Coordination. An idea in Henri Fayol's purposive theory of enterprises. In this theory, performing the management function of an enterprise is necessary in effectuating the intent of an enterprise. Coordination is a constitutive function of management, as is planning, directing, and controlling. Coordination is also an idea in Henry Mintzberg's (1983) theory of organization design. That theory is unlike Fayol's in that it is about organizations, as contrasted with enterprises. The idea that coordination is a necessary function in organizations lies at the heart of Mintzberg's purposive theory of organizations. Coordination is discussed specifically in Chapter 7.

Creating public value. An idea in Mark Moore's (1995) purposive theory of government, public programs, organizational strategy, and executive leadership at the apex of public organizations. In this theory, creating public value is what public programs properly do; it is their proper function; it is what they effectuate. This idea is meant to be just as true of public programs that deliver obligations to the entire citizenry as it is to public programs that provide services to populations of individuals. From that idea, Moore's theorizing moves in two directions. One was to be more specific about what is the proper function of programs generically; another was to be more specific about the costs of programs generically. In his theory, the proper function of public programs is to fulfill a citizenry's collective political aspirations about conditions prevailing in the society; it is decidedly not to satisfy individual wants and needs. When collective political aspirations are realized, public value has thereby been created. It follows that the intent of any specific public program is properly to realize such political aspirations. Turning to the other direction of theorizing, a program's adequacy as an effectuator of intent depends on the costs generated by its functioning. In Moore's theory, the idea of cost includes such effects as a reduction of individual consumption due to the need for the government to fund a program; reduction of individual liberty, arising specifically when the program delivers obligations to the citizenry; and a residual category of costs that are borne by citizens in co-producing public services or complying with obligations. In straightforward economizing terms, the higher the cost, the less public value is created, all things 
considered. This purposive theory provides a very general framework for ideation and deliberation about the intent of any specific public program, as well as a general guide for specifying a program's system-designs and plans. The idea of public value creation has gradually become widely referred to in the field of public administration, though this specific theorization of it has not always been preserved. These matters are discussed primarily in Chapter 2.

Design-focused case studies. Case studies conducted within a professional discipline, tied to a kind of purposeful phenomenon. In public management, design-focused case studies are about public organizations, design-projects, and/or the professional activities of sense-making, designing, argumentation, and designing. Design-focused case studies are unlike stereotypical case studies in being about kinds of purposeful as distinct from empirical phenomena. Design-focused case studies answer questions such as what was a purposeful phenomenon for; what did it consist in; and how did it work. Answers to such questions reflect mechanism-intent style purposive theorizing about the kind of purposeful phenomenon of which the case is a token. A design-focused case study's "take-aways" are not lessons but are rather design-precedents (Lawson 2004) within a professional discipline. Drawing analogies between historicallyexisting purposeful phenomena - that is, design precedents - and purposeful phenomena-in-the-making is a significant part of the professional activity of designing. These ideas are discussed in Chapters 6 and 7.

Design-precedent. An idea in the purposive theory of public management. Design-precedents are used in channeling the professional activity of designing. The use involves generative, critical thinking, typically involving exploration of close and distant analogies between a given historical purposeful phenomenon and another that is still being formulated (or designed). In a professional discipline, design-precedents result from design-focused case studies. (See the entry on that term, above.) This idea is discussed primarily in Chapter 6.

Design-projects. This term refers to ideas discussed by Herbert Simon (1996) in Chapter 5 of Sciences of the Artificial. Simon discussed how designs for artificial systems are created within organizations, to the point that decisions are made to construct, fabricate, or otherwise realize them. From the standpoint of this book, Simon presented a purposive theory of "design-projects" within enterprises. This terminology is used even though Simon did not phrase his discussion in terms of projects - and even though design-projects include decision-making in organizations. While the present book borrows the idea of design-projects from Simon, it develops this idea in concert with other aspects of its purposive theorizing of enterprises, generally, and of public organizations, more specifically. For instance, in Chapter 4 and 5, design-projects are presented as mechanisms for performing the enterprise-functions that effectuate enterprise-intent; further, design-projects are presented as consisting in designing and decision-making scenario-processes; and, beyond that, design-projects are presented as being constituted by the professional activities of sense-making, designing, argumentation, and dramatization. 
The idea of design-projects is also used to formulate a neo-Simonean/postMoore synthesis of purposive theorizing about public management, discussed in Chapters 2 and 3. Design-projects are discussed at length in Chapter 4, where the literature featured consists in Simon (1996), van Aken and Berends (2018), and Barzelay and Campbell (2003).

Designing. This is one of four professional activities within a purposive theory of public management, along with sense-making, argumentation, and dramatization. Designing plays an important role within design-projects. Designing - considered as a professional activity - involves generative, critical thinking about professional knowledge within a professional discipline, whether such knowledge takes the form of purposive theories or design-precedents. The literature on designing provides many lines of purposive theorizing of designing; lively debates about creating purposeful phenomena, and artificial systems specifically, can be found there. Chapter 4 calls attention to a purposive theory of designing as formulated by Nigel Cross (2008), while emphasizing his ideas about problem- and solution-structuring, presented in Chapter 1 of his book.

Dramatization. This is one of four professional activities within a purposive theory of public management, along with sense-making, designing, and argumentation. Dramatization creates social realities through the stage-managed projection of verbal and non-verbal signs, some of which represent relationships among actors in scenes. This professional activity has, in effect, been theorized by Erving Goffman (1959), and it has been discussed in the literature on rhetoric (e.g., Simons 2001, Kaufer and Butler 1996). This theorization has not generally entered into mechanism-intent style purposive theorizing of public organizations and professional practice, though there are definitely traces of this in literature that furnish designprecedents about public organizations (e.g., Mashaw 1981, Hilgartner 2000). A brief discussion of dramatization is placed toward the end of Chapter 4.

Embodiment designs. This term, like conceptual designs (see above), is drawn from purposive theorizing about engineering design (Cross 2008). Dating back to late nineteenth-century Germany, this purposive theory theorizes designing as a sequential stage process. This theory holds that the second stage should eventuate in a purposeful phenomenon's embodiment design. A proper embodiment design fits with a conceptual design, with the relation being that a purposeful phenomenon's embodiment design's role is to implement a settled conceptual design. The two representations are meant to be complementary, in being continuous in substance but different in degree of specificity. A proper embodiment design is specific in ways that a proper conceptual design is not. A proper embodiment design is more specific than a proper conceptual design about what a given purposive phenomenon consists in and how it works. In the design-oriented professional discipline of public management, mechanisms are theorized as scenario-processes with context-activity-outcome dynamics. A proper embodiment design is reasonably specific, but not totally definitive, about such scenario-processes and their interconnections in place and time. 
Enterprise-Functions. An idea in Henri Fayol's purposive theory of enterprises. Fayol's enterprise-functions were management, technical, commercial, security, accounting, and finance. This purposive theory is based on an analogy between enterprises and organisms as they have been theorized in biology since the work of Aristotle (see Ariew and Perlman 2002). For a given organism, it is necessary that its functions (e.g., respiration) be performed adequately if it is to survive and thrive; uncorrected deficiencies can be disabling or fatal. Also in biology, functional necessities are uniform within a species. In biology, the mechanisms for performing an organism's respective functions are uniform within the species. In Fayol's purposive theory, enterprises are uniform in their functional necessities, but not uniform in the mechanisms for performing them. (There is no one best way.) This has the implication that the enterprise-functions in Fayol's theory are not as clearly differentiated compared with the differentiation of organismfunctions in biological research; as such Fayol's enterprise-functions and management-functions are more like lists than a system analysis. But they are useful as a loose taxonomic framework within the sort of purposive theory that Fayol's theory is meant to be. These matters are discussed primarily in Chapters 2, 3, and 5 .

Enterprises. The overarching idea in Henri Fayol's theory of enterprises. In this purposive theory, all enterprises have functional necessities, among which one is management. By this argument, an enterprise will have lower prospects of fulfilling its purposes if the performance of its necessary functions is deficient. Enterprises consist in intent-effectuating mechanisms, some of which are artificial systems, with predictable input-activity-output profiles, some of which are scenario-like purposeful phenomena, with patterns of context-activityoutcome dynamics. Enterprises are sites for professional practice. An elaborate mechanism-intent, purposive theory of business enterprises is Porter (1985). A thematically focused mechanism-intent, purposive theory of public organizations is Bryson (2018). A different style of purposive theorizing of public organizations, with casuistical overtones, is Moore (1995). These matters are discussed primarily in Chapters 2, 3, and 5.

Fayol, Henri. Best known as a late nineteenth-century theorist of enterprises. See, enterprises.

Goffman, Erving. A leading North American sociology professor until his untimely death in 1983, associated with the so-called Chicago School of Sociology. Author of The Presentation of Self in Everyday Life (1959). Goffmann originated a current of micro-sociological theorizing and case study research, with which the term "dramaturgical" is associated. This line of theorizing concentrates on how social realities, as experienced by individuals, result from how and what people, to an extent deliberately, present to others as "true" about social entities and processes. It also concentrates on how social realities, so constructed, affect the course of social life, by virtue of the meaning individuals attribute to scenes and social relations. In the present book, Goffman's 
dramaturgical theory is the basis for purposive theorizing about the professional activity of dramatization. These matters are briefly discussed at the end of Chapter 4.

Intent. An idea that plays a significant role in such representations of a purposeful phenomenon. The role points to a state of affairs, or continuing process, whose effectuation is sought through a purposeful phenomenon's mechanisms. In the design-oriented professional discipline of public management, the intent of public organizations, generically, is to create public value.

Lynn, Laurence E., Jr. An American professor of public policy, who holds emeritus appointments at Texas A \& M University and the University of Chicago. Lynn entered the field of public policy through economics: he obtained his PhD in Economics at Yale University, and he then worked in the U.S. Federal government in positions for program planning and evaluation from the late 1960s through the late 1970s. During the late 1970s through the start of the 1980s, Lynn was a professor of public policy at Harvard's Kennedy School of Government. He subsequently moved to the University of Chicago, holding appointments in two professional schools: public policy and social administration. Lynn served as Dean for the latter. During the 1990s, Lynn became an outspoken critic of certain approaches to both teaching and researching on public management, which were somewhat prevalent within public policy schools most prominently so at the Kennedy School. Lynn's first book-length statement of his views on this matter appeared in Public Management as Art, Science, and Profession (1996). That book is a reference point for the present one, Public Management as Design-Oriented Professional Discipline. Lynn's book was similar to the present book in identifying public management as a professional discipline; however, these books' substantive views about public management, as a professional discipline, are sharply divergent, as discussed in Chapter 8.

Management-function. An idea in Henri Fayol's purposive theory of enterprises. In this theory, an enterprise's six functions include the managementfunction, as well as technical, commercial, finance, accounting, and security functions. The management-function is enabling of the performance of these other functions. The constitutive functions of management are planning, directing, coordinating, and controlling. Any of these functions is performed by mechanisms, which can be theorized as interlocking scenario processes within organizations. Planning is distinctive in that it eventuates in standards and plans, as well as other representations of intent and mechanisms to effectuate them. The term is not currently fashionable: designing is more fashionable. Directing is also not currently fashionable; leadership is more so. Controlling is distinctive in comparison with coordination in that it is based on standards, which can come from plans or other sources. Controlling is not currently fashionable; monitoring is more so. These matters are discussed generally in Chapters 2 and 3, and they are illustrated concretely in Chapter 7. 
Mechanism-intent thinking. A style of theorizing purposeful phenomena, whether types or particulars. Standard questions discussed in such theorizing concern what a purposeful phenomenon is for; what it consists in; and how it works. The answers reflect lineages and precedents within a professional discipline. Not all purposive theorizing and analysis of purposeful phenomena is guided by these ideas of mechanism-intent theorizing. The mechanism-intent style of purposive theorizing and case analysis is characteristic of a design-oriented professional discipline. The idea is introduced implicitly in Chapter 1 and explicitly in Chapter 3.

Mechanisms. An idea that plays a key role in mechanism-intent thinking about purposeful phenomena. A purposeful phenomenon's mechanisms effectuate its intent. In some purposive theories of enterprises, mechanisms effectuate intent by performing one or more of its constitutive functions. Mechanisms consist in processes, some of which are theorized as scenario-processes. Scenarioprocesses begin with their initial conditions and terminate in their outcomes. Scenario-context channels scenario-activity, involving interactions among flows of activity, usually on a range of social scales. Scenario-activity eventuates in scenario-outcomes. These matters are primarily discussed in Chapters 4, 5 and 6.

Modern management school. The purposeful phenomenon to which this term referred first came to exist in North American universities during the late 1940s (Augier and March 2011). A token of this type was the Graduate School of Industrial Administration (GSIA) at Carnegie Institute of Technology, in Pittsburgh, Pennsylvania. As presented by its proponents, the modern management school would do for the field of management (in North America) what the modern medical school had done for the field of medicine, in the half-century since its inception at Johns Hopkins University. The modern management school was pre-dated by the Wharton School at the University of Pennsylvania and the Graduate School of Business Administration at Harvard (HBS). GSIA and HBS became, in effect, rivals. GSIA recruited heavily from the Cowles Commission for Research in Economics at the University of Chicago. Nobel prize-winning work on modern finance theory was undertaken at GSIA. A field of marketing was developed along lines reflecting disciplinary research in economics and psychology. GSIA's initial faculty included Herbert Simon, who had connections to the Cowles Commission, but who had done his doctoral work in political science and had worked to develop, in effect, a professional discipline of public administration. Simon became an internal critic of the modern management school; he was not enamored with the idea that the modern medical school provided a suitable template for a professional discipline within the field of management (Augier and March 2011). He set off to develop fundamental knowledge about decision-making in organizations, and he parlayed this work into an approach to management as problem-solving, especially involving the creation of novelty. The present book steers wide of the modern management school notion of management as a professional discipline, while incorporating Simon's ideas, which were consonant with neither 
the modern medical school nor with the HBS approach. These matters are discussed in Chapters 2 and 8.

Moore, Mark. Author of Creating Public Value: Strategic Management in Government (Moore 1995). During his entire academic career, Moore was based at Harvard University, primarily at the Kennedy School of Government, but he was also associated with the Graduate School of Education and Harvard Business School. He has had major involvements with public management teaching outside the U.S., especially with the Australia-New Zealand School of Government. Creating Public Value exemplifies a Harvard-style approach to theorizing enterprises and the professional practice of management, and it constitutes a Harvard-style approach to theorizing public organizations and the action profile of individuals in a role theorized as that of a public manager. This book is featured in the Public Management Gallery Tour, presented in Chapter 4 , in the section on purposive theories of public organizations.

Pattern language. This term refers to a body of conventions for representing mechanism-intent thinking about enterprise-like purposeful phenomena, including public organizations. These conventions can be placed in two groups, by drawing on the distinction, notable in the professional discipline of engineering, between a machine-like system's conceptual design and its embodiment design. Reflecting Fayol, the conceptual design of enterprises involves the identification of enterprise-intent, on the one hand, and enterprise-functions, on the other. Within the pattern language, performing an enterprise's functions effectuates an enterprise's intent. In such thinking, the performance of a given function is dependent on the performance of one or more other functions (as is true of organisms, as well). Under the conventions of pattern language, this relation of inter-functional dependency is expressed in terms of functions enabling other functions. Thus, overall pattern language of an enterprise's conceptual design goes along the lines of: functions effectuate intent, while functions enable functions. Turning to the second group of conventions, the embodiment designs of enterprises are constituted by mechanisms and their inter-relations. A given mechanism, viewed in isolation from other mechanisms, is a scenario-process with a distinct context-activities-outcome profile. When detail is added to the characterization of a scenario-process, clarity about how contexts channel activities and how activities eventuate in outcomes is achieved - making the causal properties of scenario-processes more explicit. An embodiment design is constituted by relations among the totality of its scenario-processes. The pattern language express this idea in terms of one scenario-process structuring another. The pattern language also expresses the relation between an enterprise's embodiment and conceptual designs: the former implements the latter, in service of effectuating enterprise-intent, as presented in its conceptual design. These matters are discussed in Chapter 3 and the ideas are illustrated concretely in Chapter 7.

Process context factors. Within purposive theorizing of enterprises, these are aspects of mechanisms - specifically, of scenario-processes. (The term comes 
from Barzelay 2007.) In relation to scenario-process activity, process context factors are dynamically stable conditions - specifically those whose presence in the scenario is due to scenario-processes that are cast as being contextual in relation to those on which attention is focused, for analytical or problem-solving purposes. This idea is discussed in Chapters 6 and 7.

Process design features. Within purposive theorizing of enterprises, these are aspects of mechanisms - specifically, of scenario-processes. (The term comes from Barzelay 2007.) In relation to scenario-process activity, process design features are dynamically stable conditions - specifically those whose presence in a scenario-process is central to the line of purposive theorizing that is being examined. This idea is discussed in Chapters 6 and 7.

Processual sociology. A school of thought in sociology with deep roots in the Chicago School of Sociology. Major intellectual statements of this school of thought include Abbott (2001) and Abbott (2016). While this school of thought does not lay out purposive, design-oriented theorizing or case analysis, it has much to offer in analyzing and designing scenario-processes, because its theoretical ideas can be used to make explicit how scenario-context channels scenario-activities and how scenario-activities eventuate in scenario-outcomes. Processual sociology provides a tradition and precedents for theorizing such process dynamics. Part of processual sociology revolves around the idea that causation in social processes can be theorized in terms of social mechanisms, with examples of such mechanisms being frame alignment (McAdam, Tarrow, and Tilly 2001), actor certification (McAdam, Tarrow and Tilly 2001), opportunity attribution (McAdam, Tarrow, and Tilly 2001), homophily and heterophily in networks (Kilduff and Tsai 2003), and performance feedback (Greve 2003). The relevance of these ideas to design-focused case studies was presented in Barzelay (2007) and, in the present volume, is discussed in Chapter 6 and demonstrated in Chapter 7.

Professional discipline of public management. This book furthers the idea that public management is (or, can be) a professional discipline (Lynn 1996). Any professional discipline is essentially constituted by two linked enterprises: discipline-development and teaching-and-learning for would-be and actual professional practitioners. As represented here, the teaching-and-learning enterprise effectuates better professional practice, encompassing professional activities, design-projects, and performing the management function within public organizations. It also effectuates an expanding community of professional practitioners who tackle opportunities and challenges through design-focused public management practice. The teaching-and-learning enterprise's constitutive functions are acquiring professional knowledge, improving professional abilities, and strengthening professional competence. As for the discipline-development enterprise, it has a role in enabling the teaching-and-learning enterprise, while its constitutive functions are strengthening disciplinary identity, expanding professional knowledge, and faculty development. 
Professional disciplines. A professional discipline is a domain within networks of institutions of higher education and research. Unlike scientific disciplines, which are generally focused on kinds of empirical phenomena, professional disciplines are generally focused on kinds of purposeful phenomena, as well as on teaching and learning about professional practice concerned with them. A professional discipline can be classified as a science of the artificial (Simon 1996) when its kinds of purposeful phenomena are artificial systems, like machines and buildings. Professional disciplines that are not sciences of the artificial do not have a standard label. The term "profession" on its own is problematic for many professional disciplines (Abbott 2016 and Schön 1983), including management (Augier and March 2011). Any professional discipline is essentially constituted by two linked enterprises: discipline-development and teaching-and-learning for would-be and actual professional practitioners. As represented here, the constitutive functions of a professional discipline's teaching-and-learning enterprise are acquiring professional knowledge, improving professional abilities, and strengthening professional competence. The discipline-development enterprise enables the teaching-and-learning enterprise. Its constitutive functions are strengthening disciplinary identity, expanding professional knowledge, and faculty development. The term "design-oriented professional disciplines" refers to professional disciplines that (a) are tied to kinds of purposeful phenomena and (b) are concerned with the creation of novelty, to the point that their teachingand-learning and discipline-development enterprises are strongly concerned with design-projects and the professional activity of designing. The category, design-oriented professional disciplines - a term in this book - includes the category, sciences of the artificial (Simon 1996), but it is wider: it includes professional disciplines whose kinds of purposeful phenomena are enterprises, an example of which is public organizations.

Professional knowledge. The state of debate within a professional discipline about the purposeful phenomena to which they are tied, as well as about professional practice as it relates to that discipline. Forms of professional knowledge within a professional discipline include purposive theorizing and design-precedents. This idea is discussed throughout the book, but comes into particular focus in Chapters 1 and 8.

Public organizations. A term borrowed from Moore (1995). In that book, public organizations are purposeful phenomena, as is appropriate to a study within the professional discipline of public management, rather than empirical phenomena, as would be appropriate to a study within social science disciplines. In theorizing public organizations as purposeful phenomena, Moore borrows ideas that have been used to theorize enterprises generally. In doing so, he theorizes that public organizations are for creating public value. Aligned with this way of theorizing public organizations, public programs are presented as one of their most significant aspects. In his theory, public organizations create public value by combining operational capacity with support from their authorizing environment. Whether the term "public organizations" is the best label for this purpose- 
ful phenomenon, as theorized, is a debatable point; but Moore's book establishes a convention for using this label for the enterprise-like purposeful phenomenon being theorized. These matters are discussed in Chapters 2, 3, and 4 .

Purposeful phenomena. A term that widens Herbert Simon's (1996) idea of artificial phenomena. As presented in Sciences of the Artificial, artificial phenomena include artificial systems and the design-projects that create them. Purposeful phenomena are tied to professional disciplines. Public management's purposeful phenomena include public organizations, design-projects, and the professional activities of sense-making, designing, argumentation, and dramatization.

Purposive theory. Theories of purposeful phenomena are formulated (and critically examined) within professional disciplines, for use in professional practice. In public management, purposive theorizing concerned public organizations, design-projects, and such professional activities as sense-making, designing, argumentation, and dramatization. Purposive theories constitute professional knowledge and, as such, are appropriate items of critical discussion in the teaching and learning enterprise of the public management discipline. This idea is examined in some depth in Chapters 2-5.

\section{Scenario-processes. See mechanisms.}

Sciences of the artificial. A collection of professional disciplines concerned with professional practice in creating types of artificial systems, whether physical or digital. The term is also the title of a book by Herbert A. Simon (1996). In the present book, Simon's idea of a science of the artificial is a precedent for the idea of public management as a design-oriented professional discipline; see, especially, Chapter 8.

Sense-making. This is one of four professional activities within a purposive theory of public management, along with designing, argumentation, and dramatization. The outcome of sense-making activities include observations about specific situations and directions for problem-solving. In public management, the substance of such observations and problem-solving ideas reflects purposive theories of public organizations and of design projects, as they are used in professional practice. Sense-making is discussed briefly in Chapter 4 .

Simon, Herbert A. A leading twentieth-century academic in social science. Studied for a $\mathrm{PhD}$ in Political Science from the University of Chicago in the 1930s and 1940s, with a focus on public administration. During the 1940s and 1950s, Simon was a professor at the Graduate School of Industrial Administration of Carnegie Institute of Technology. During the 1960s to his death in 1991, Simon was professor of computer science and psychology at Carnegie-Mellon University. He is most known in the social sciences for developing positive theories of human decision-making in which rationality is procedural and concerned with incomplete information, ignorance, and limits to the calculative capacities 
of the human mind. The single-word term that became the standard way to refer to this theory is satisficing. Simon was awarded the Nobel Prize in Economics in 1978 for this work. What is relevant for the present book is Simon's Sciences of the Artificial, the final edition of which came out in 1996. Simon argued that fields of research and education that are tied to professional practice, as in engineering, architecture, and management, ought to be concerned with designing. In Chapter 5, Simon outlined (what we call here) a purposive theory of designing that, in being abstract and generic, was meant to apply uniformly to any field of professional practice. What Simon wrote proved influential as the interdisciplinary field of design studies developed; and this field, in turn, has come to influence the field of management, though only to a degree. These considerations are discussed here in Chapters 2, 3, and 8.

Social mechanisms. Within sociology, a social mechanism is a robust, but not law-like empirical phenomenon. Social mechanisms can be discovered through theorization and empirical study. Once they have been identified, they can be used to gain causal insight into kinds of social entities and processes, by way of explanatory argumentation of particular entities and episodes. Many mechanisms in sociology provide causal and descriptive idealizations of scenario-processes, whose outcomes eventuate from combinations of time-specific factors, some of which are contextual in being dynamically stable properties of situations, while others are constitutive of activities. Examples of such mechanisms are frame alignment, homo- and hetero-phily in networks, and performance feedback (see Chapter 7). 
Michael Barzelay - 9781788119108

Downloaded from PubFactory at 04/26/2023 03:54:57AM via free access 